Research Article

Check for updates

OPEN ACCESS

Received: Apr 30, 2019

Accepted: Jul 12, 2019

*Correspondence:

Chunhui Suh

Department of Occupational and

Environmental Medicine \& Institute of

Environmental and Occupational Medicine,

Pusan Paik Hospital, Inje University, 75 Bokji-ro,

Busanjin-gu, Busan 47392, Korea.

E-mail: chsuh@paik.ac.kr

Copyright (c) 2019 Korean Society of

Occupational \& Environmental Medicine

This is an Open Access article distributed

under the terms of the Creative Commons

Attribution Non-Commercial License (https://

creativecommons.org/licenses/by-nc/4.0/)

which permits unrestricted non-commercial

use, distribution, and reproduction in any

medium, provided the original work is properly cited.

ORCID IDS

Chunhui Suh (D)

https://orcid.org/0000-0002-6077-5380

Jae Won Yang (iD

https://orcid.org/0000-0003-0292-6301

Abbreviations

PERMA: Positive emotion, Engagement, Relationships, Meaning, and Accomplishment; MHC-SF: Mental Health Continuum-Short Form; UWES: Utrecht Work Engagement

Scale; KOSS-SF: Korean Occupational

Stress Scale-Short Form; MBI-GS: Maslach Burnout Inventory-General Survey; PWI-SF: Psychosocial Well-being Index-Short Form;

CFA: confirmatory factor analysis; $\mathrm{CFI}$ :

comparative fit index; TLI: Tucker-Lewis

index; RMSEA: root mean square error of

\section{Korean translation and validation of the Workplace Positive emotion, Engagement, Relationships, Meaning, and Accomplishment (PERMA)-Profiler}

\author{
Seong Pil Choi, Chunhui Suh (D) *, Jae Won Yang (D), Byung Jin Ye, Chae Kwan Lee, \\ Byung Chul Son, and Maro Choi
}

Department of Occupational and Environmental Medicine \& Institute of Environmental and Occupational Medicine, Pusan Paik Hospital, Inje University, Busan, Korea 
approximation; SRMR: standardized root mean square residual; EX: exhaustion; $\mathrm{CY}$ : cynicism; PE: professional efficacy; P: positive emotion; E: engagement; R: relationships; M: meaning; A: accomplishment; $\mathrm{N}$ : negative emotion; $\mathrm{H}$ : health; df: degrees of freedom.

Funding

This study was supported by research grant of the Korean Society of Occupational and Environmental Medicine in 2018.

Competing interests

The authors declare that they have no competing interests.

Authors contributions

Conceptualization: Choi SP, Suh C. Data curation: Choi SP; Formal analysis: Choi SP; Investigation: Suh C, Lee CK, Son BC, Ye BJ, Choi M, Yang JW; Writing - original draft: Choi SP, Suh C; Writing - review \& editing: Suh C, Lee CK, Son BC, Ye BJ, Choi M, Yang JW. friendships, and better physical health [2]. The role of well-being in the professional environment is important. There are 3 broad approaches to the understanding of wellbeing at work. The 3 approaches consider individual health of workers, mental illness of organizations and potential societal consequences. These eventually affect productivity as well [3-7]. Therefore, measurement of the abstract concept of well-being in the workplace is important for research and practice.

No single best model of well-being exists, but different conceptualizations can aid examination of the abstract construct of well-being and provide concrete domains that can be measured and developed. Several measurement instruments with positive approaches address mental health in general; most of these measures do not include the occupational arena [8]. Specifically, we focus on the 5 domains of the Positive emotion, Engagement, Relationships, Meaning, and Accomplishment (PERMA) theory defined by Seligman [9]: positive emotion (P), engagement (E), relationships (R), meaning (M), and accomplishment (A). Kern developed the Workplace PERMA-Profiler based on PERMA theory. Application of the PERMA factors in the different contexts of life and work suggested that the concepts of the original PERMA-Profiler and Workplace PERMA-Profiler are distinct. The Workplace PERMA-Profiler is adjusted to the workplace context, enabling the multidimensional evaluation of workers' well-being. The PERMA-Profiler has shown acceptable psychometric properties in assessments conducted with several different international samples [10].

In Korea, the original PERMA-Profiler has been translated and used in some studies, but its validity has not been reported [11,12]. The Workplace PERMA-Profiler has not been translated into Korean or validated in Korean studies. In this study, the Workplace PERMAProfiler was translated into Korean, and the Korean version was validated.

\section{METHODS}

The Workplace PERMA-Profiler was translated according to the International Society for Pharmacoeconomics and Outcomes Research task force guidelines [13,14], as follows. 1) Preparation; we obtained permission from the developer, Peggy Kern, to use and translate the Workplace PERMA-Profiler into Korean. 2) Forward translation; we had 2 independent translators translate the Workplace PERMA-Profiler into Korean; the translators were fully capable of translating the instrument with sufficient explanation. 3) Reconciliation; the translation panel compared and merged 2 versions of the newly translated the Workplace PERMA-Profiler and the original PERMA-Profiler as references [11,12], yielding a final single forward-translated Profiler. 4) Back translation; a professional translator translated the Korean version of the Workplace PERMA-Profiler back into the original language. 5) Back translation review; the developer compared the back-translated version of the Workplace PERMA-Profiler with the original instrument to identify any discrepancies. 6) Cognitive debriefing; we tested the translated Workplace PERMA-Profiler with 34 respondents to evaluate its understandability and interpretation. 7) Proofreading; a Korean linguist reviewed the final Profiler and corrected minor errors, such as typographic and grammatical errors. The full version of the Korean Workplace PERMA-Profiler was attached to Appendices $\mathbf{1}$ and $\mathbf{2}$.

The validation study was conducted as an online survey. The internal consistency, structural validity, and convergent and divergent validity of the Korean version of the Workplace PERMA-Profiler were investigated. 


\section{Study subjects}

Participants were drawn from workers registered with an internet survey company, which had access to more than 1,300,000 potential participants in Korea, and recruited participants based on their gender, age and residential area. The survey company recruited Korean workers who lived in Korea and were aged $\geq 18$ years from their pool of potential participants until the target number was reached. In general, it is recommended that at least 10 subjects per scale item be included for factor analysis [15], and more than 100 subjects for Cronbach's alpha values [16]. To ensure the acceptability of the statistical analysis, we decided to use a subjectsto-item ratio $>10$. Eligible workers who agreed to participate in the online survey were given access to the self-report questionnaire. The instructions assured the protection of personal information and only those who wanted to participate in this study were asked to complete the questionnaire. Participating workers were awarded points for survey completion that could be cashed out and used for shopping. In total, 326 workers completed the web-based questionnaire; $3 \%$ of respondents with short response times were excluded because their responses were considered to be inadequate. The final sample consisted of 316 participants.

\section{Measures}

Participants completed an online self-reported survey that included the Korean Workplace PERMA-Profiler and questions from the Mental Health Continuum-Short Form (MHCSF), Utrecht Work Engagement Scale (UWES), Korean Occupational Stress Scale-Short Form (KOSS-SF), Maslach Burnout Inventory-General Survey (MBI-GS), and Psychosocial Well-being Index-Short Form (PWI-SF). As questionnaires that measure concepts similar to those measured by the Korean Workplace PERMA-Profiler, we used the MHC-SF, which measures three dimensions of mental well-being in life, and the UWES, which measures work engagement. To measure the opposite concept of work engagement, we used the MBIGS, which measures burnout. To assess occupational stressors and stress responses, we used the KOSS-SF and PWI-SF. The final section of the survey consisted of basic demographic questions about participants' age, gender, level of education attained, residential area, job type, and employment status.

\section{The Korean Workplace PERMA-Profiler}

The Korean version of the Workplace PERMA-Profiler was used to measure multidimensional well-being at work. It includes the 15 main PERMA items ( 3 items per domain) and 8 filler items that assess overall well-being (one item), physical health ( 3 items), negative emotion (3 items), and loneliness (one item). To allow for a broad range of responses with sufficient variation, responses are structured by a Likert scale ranging from 0 to 10 , with 0 indicating extremely low levels and 10 indicating extremely high levels. Composite scores for each domain were calculated by taking the mean of the 3 domain items [17].

MHC-SF

The MHC-SF measures positive mental health. It comprises 14 items on emotional ( 3 items), psychological (6 items), and social (5 items) well-being. Total scores range from 0 to 70 , with higher scores reflecting greater mental well-being in life. Cronbach's alpha value for the K-MHC-SF in a previous study was 0.93 [18].

\section{UWES}

Work engagement was measured using the UWES-9 [19], which investigates experience using the constructs of vigor, dedication, and absorption. Responses to items are given on a 
frequency scale ranging from 0 (never) to 6 (always). Cronbach's alpha value for the UWES-K in a previous study was $0.91[20]$.

KOSS-SF

Job stress was measured using 24 items of the KOSS-SF, a self-reported questionnaire for the estimation of unique and specific occupational stressors among Korean employees. Chang et al. [21] validated the reliability of the KOSS in a nationwide epidemiological study (the NSDSOS Project) conducted in Korea.

The KOSS-SF subscales used in this study were job demands ( 4 items, Cronbach's alpha = $0.58)$, insufficient job control ( 4 items, Cronbach's alpha $=0.67$ ), inadequate social support ( 3 items, Cronbach's alpha $=0.55)$, job insecurity $(2$ items, Cronbach's alpha $=0.73)$, the organizational system ( 4 items, Cronbach's alpha $=0.67$ ), lack of rewards ( 3 items, Cronbach's alpha $=0.72)$, and occupational climate $(4$ items, Cronbach's alpha $=0.71)$. Each questionnaire item was rated on a Likert scale ranging from 1 (not at all) to 4 (very much).

MBI-GS

Burnout was assessed with the Korean version of the MBI-GS [22]. The MBI-GS has three subscales: exhaustion (EX), cynicism (CY), and professional efficacy (PE). All items were scored on a 7-point frequency scale ranging from 0 (never) to 6 (always). High EX and CY scores and low PE scores are indicative of burnout. Cronbach's alpha values for the EX, CY, and PE subscales in a previous study were $0.90,0.81$, and 0.86 , respectively [23].

PWI-SF

Psychosocial stress responses were evaluated with the PWI-SF, which was developed based on the General Health Questionnaire-60 to determine levels of psychosocial stress responses in the general population. Its reliability and validity have been established for Korean workers. Respondents score each item on a 4-point Likert scale, and scores are summed to determine the levels of psychosocial stress responses, with higher scores indicating greater stress levels [24]. Cronbach's alpha value for the PWI-SF in a previous study was 0.88 [25].

\section{Data analysis}

To test reliability, the internal consistency of the Korean Workplace PERMA-Profiler was assessed by calculating Cronbach's alpha values for the total score and individual factor scores (i.e., P, E, R, M, and A) [10].

To confirm the 5 -factor structural validity of the instrument, confirmatory factor analysis (CFA) was conducted for the 15 items using robust maximum-likelihood estimation. The original 5 -factor model and a 1-factor model were tested using the following model fit indices: the $\chi^{2}$ test, comparative fit index (CFI), Tucker-Lewis index (TLI), root mean square error of approximation (RMSEA), and standardized root mean square residual (SRMR). We considered CFI and TLI values $>0.95$ and RMSEA and SRMR values $<0.06$ to indicate good model fit [26]. Pearson's coefficients $(r)$ of correlation between the PERMA factors and other questionnaires including MHC-SF, KOSS-SF, UWES, MBI-GS, and PWI-SF were calculated to examine convergent and divergent validity. We used IBM SPSS AMOS version 25 (IBM Corp., New York, USA) for the analyses. 


\section{Ethics statement}

The Institutional Review Board of Inje University Busan Paik Hospital exempted this study from review (no. 18-0236) because it did not involve the collection or recording of personal identifiable information and did not violate the rights of or harm of any study subject. All authors have seen and approved manuscript.

\section{RESULTS}

\section{Participant characteristics}

Table 1 shows the demographic characteristics of the participants. The majority of participants had graduated from university $(65.5 \%)$ or had some college education $(21.8 \%)$. Most participants were permanent workers contracted with company at least 1 years of employment $(98.1 \%)$ and were engaged as office clerks (65.8\%). The ages and regions of the participants were distributed evenly.

Table 1. Participant demographics $(n=316)$

\begin{tabular}{|c|c|}
\hline Characteristics & No. $(\%)$ \\
\hline \multicolumn{2}{|l|}{ Gender } \\
\hline Men & $155(49.1)$ \\
\hline Women & $161(50.9)$ \\
\hline \multicolumn{2}{|l|}{ Age } \\
\hline $20-29$ & $69(21.8)$ \\
\hline $30-39$ & $79(25.0)$ \\
\hline $40-49$ & $85(26.9)$ \\
\hline$\geq 50$ & $83(26.3)$ \\
\hline \multicolumn{2}{|l|}{ City/province } \\
\hline Seoul & $56(17.7)$ \\
\hline Gyeonggi/Gangwon/Incheon & $54(17.1)$ \\
\hline Chungbuk/Chungnam/Daejeon/Sejong & $54(17.1)$ \\
\hline Jeonbuk/Jeonnam/Gwangju/Jeju & $52(16.5)$ \\
\hline Gyeongbuk/Daegu & $50(15.8)$ \\
\hline Gyeongnam/Busan/Ulsan & $50(15.8)$ \\
\hline \multicolumn{2}{|l|}{ Job type } \\
\hline Managers & $24(7.6)$ \\
\hline Professionals and related workers & 25 (7.9) \\
\hline Technical and paraprofessional & 25 (7.9) \\
\hline Office clerks & $208(65.8)$ \\
\hline Service workers & $7(2.2)$ \\
\hline Sales workers & $8(2.5)$ \\
\hline Skilled agricultural, forestry and fishery workers & $3(0.9)$ \\
\hline Crafts and related workers & $5(1.6)$ \\
\hline Machine operating and assembling workers & $8(2.6)$ \\
\hline Elementary workers & $3(0.9)$ \\
\hline \multicolumn{2}{|l|}{ Employment status $^{\mathrm{a}}$} \\
\hline Permanent & $310(98.1)$ \\
\hline Temporary/daily & $6(1.9)$ \\
\hline \multicolumn{2}{|l|}{ Educational status ${ }^{b}$} \\
\hline High school (12 or 13 years) & $40(12.7)$ \\
\hline College ( 14 or 15 years) & $69(21.8)$ \\
\hline University (16 years) & $177(56.0)$ \\
\hline Graduate school (17 years) & $30(9.5)$ \\
\hline
\end{tabular}

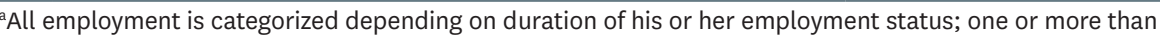
year as permanent, one month to a year as temporary, less than a month as daily employment; 'We asked the participants, 'What is your highest level of education? Please indicate the total length of time that you have attended school.' The years of schooling were written in parentheses. 


\section{Internal reliability}

Table 2 shows mean scores and Cronbach's alpha values for the PERMA factors. Cronbach's alpha values ranged from 0.70 to 0.95 .

\section{Structural validity}

Table 3 shows the results of the CFA. Standardized covariances ranged from 0.63 to 0.89 in the 5 -factors model and 0.50 to 0.87 in the 1 -factor model. The 5 -factor model showed marginally acceptable fit $\left[\chi^{2}(80)=383.05, \mathrm{CFI}=0.909, \mathrm{TLI}=0.881, \mathrm{RMSEA}=0.110, \mathrm{SRMR}=0.054\right]$. The 5 -factor model had a better fit than did the 1-factor model $\left[\Delta \chi^{2}(10)=146.93, p<0.05\right]$.

\section{Convergent and divergent validity}

Table 4 shows the Pearson's coefficients ( $r$ ) of correlation among the PERMA factors, MHC-SF, KOSS-SF, UWES, MBI-GS, and PWI-SF. The 5 PERMA factors showed a moderate to strong positive correlation with the mental well-being in life $(0.39 \leq r \leq 0.67$ in MHC-SF), work engagement ( $0.52 \leq r \leq 0.81$ in UWES), and professional efficacy subscale $(0.47 \leq r \leq 0.64)$ in burnout. Meanwhile the PERMA factors showed a moderate negative correlation with the exhaustion subscale $(-0.50 \leq r \leq-0.19)$ and cynicism subscale $(-0.51 \leq r \leq-0.37)$ in burnout, occupational stressors $(-0.59 \leq r \leq-0.30$ in total KOSS-SF), and stress responses $(-0.62 \leq r \leq$ -0.30 in PWI-SF).

Table 2. Mean scores and internal reliability $(n=316)$

\begin{tabular}{|c|c|c|}
\hline Factor/questions & Mean (standard deviation) & Cronbach's alpha \\
\hline Positive emotion & & 0.88 \\
\hline P1: At work, how often do you feel joyful? & $5.17(2.2)$ & \\
\hline P2: At work, how often do you feel positive? & $5.95(2.0)$ & \\
\hline P3: At work, to what extent do you feel contented? & $5.64(2.1)$ & \\
\hline Engagement & & 0.78 \\
\hline E1: At work, how often do you become absorbed in what you are doing? & $6.94(1.7)$ & \\
\hline E2: To what extent do you feel excited and interested in your work? & $5.48(2.2)$ & \\
\hline E3: At work, how often do you lose track of time while doing something you enjoy? & $5.84(2.1)$ & \\
\hline Relationships & & 0.83 \\
\hline R1: To what extent do you receive help and support from coworkers when you need it? & $6.51(1.8)$ & \\
\hline R2: To what extent do you feel appreciated by your coworkers? & $5.73(1.8)$ & \\
\hline R3: How satisfied are you with your professional relationships? & $6.07(1.9)$ & \\
\hline Meaning & & 0.86 \\
\hline M1: To what extent is your work purposeful and meaningful? & $6.02(1.9)$ & \\
\hline M2: In general, to what extent do you feel that what you do at work is valuable and worthwhile? & $6.57(2.0)$ & \\
\hline M3: To what extent do you generally feel that you have a sense of direction in your work? & $6.32(1.8)$ & \\
\hline Accomplishment & & 0.70 \\
\hline A1: How often do you feel you are making progress towards accomplishing your work-related goals? & $5.81(1.8)$ & \\
\hline A2: How often do you achieve the important work goals you have set for yourself? & $6.66(1.6)$ & \\
\hline A3: How often are you able to handle your work-related responsibilities? & $7.16(1.5)$ & \\
\hline Happiness, taking all things together, how happy would you say you are with your work? & $5.96(2.0)$ & - \\
\hline Overall well-being (average of the above 16 items) & $6.12(1.4)$ & 0.95 \\
\hline Negative emotion & $4.68(1.8)$ & 0.75 \\
\hline \multicolumn{3}{|l|}{ N1: At work, how often do you feel anxious? } \\
\hline \multicolumn{3}{|l|}{ N2: At work, how often do you feel angry? } \\
\hline \multicolumn{3}{|l|}{ N3: At work, how often do you feel sad? } \\
\hline Health & $5.33(1.9)$ & 0.94 \\
\hline \multicolumn{3}{|l|}{ H1: In general, how would you say your health is? } \\
\hline \multicolumn{3}{|l|}{ H2: How satisfied are you with your current physical health? } \\
\hline \multicolumn{3}{|l|}{ H3: Compared with others of your age and sex, how is your health? } \\
\hline Loneliness & $4.52(2.5)$ & - \\
\hline How lonely do you feel at work? & & \\
\hline
\end{tabular}


Table 3. Confirmatory factor analysis of the 15 items of the Korean version of the Workplace PERMA-Profiler

\begin{tabular}{|c|c|c|c|c|c|c|c|c|}
\hline \multirow{3}{*}{$\begin{array}{l}\text { Items } \\
\text { P1 }\end{array}$} & \multicolumn{2}{|c|}{ Factor loadings } & \multicolumn{6}{|c|}{ Correlation coefficients in the 5 -factor model } \\
\hline & \multirow{2}{*}{$\frac{1 \text {-factor model }}{0.82^{\mathrm{a}}}$} & \multirow{2}{*}{$\frac{5 \text {-factor model }}{0.85^{\mathrm{a}}}$} & & & & & & \\
\hline & & & & $\mathrm{F} 1(\mathrm{P})$ & $\mathrm{F} 2(\mathrm{E})$ & F3 (R) & F4 (M) & F5 (A) \\
\hline P2 & $0.79^{a}$ & $0.81^{\mathrm{a}}$ & $\mathrm{F} 1(\mathrm{P})$ & 1.00 & & & & \\
\hline P3 & $0.85^{\mathrm{a}}$ & $0.89^{\mathrm{a}}$ & $\mathrm{F} 2(\mathrm{E})$ & $0.98^{\mathrm{a}}$ & 1.00 & & & \\
\hline E1 & $0.62^{\mathrm{a}}$ & $0.63^{a}$ & F3 (R) & $0.88^{\mathrm{a}}$ & $0.86^{a}$ & 1.00 & & \\
\hline E2 & $0.87^{a}$ & $0.87^{a}$ & F4 (M) & $0.89^{a}$ & $0.99^{a}$ & $0.87^{a}$ & 1.00 & \\
\hline E3 & $0.70^{\mathrm{a}}$ & $0.70^{\mathrm{a}}$ & F5 (A) & $0.74^{\mathrm{a}}$ & $0.87^{\mathrm{a}}$ & $0.74^{\mathrm{a}}$ & $0.89^{a}$ & 1.00 \\
\hline $\mathrm{R} 1$ & $0.66^{a}$ & $0.72^{\mathrm{a}}$ & Model fit & & & & & \\
\hline $\mathrm{R} 2$ & $0.69^{a}$ & $0.77^{a}$ & $\chi^{2}(\mathrm{df})$ & & & $0)^{a}$ & & \\
\hline R3 & $0.79^{a}$ & $0.86^{a}$ & $\mathrm{CFI}$ & & & & & \\
\hline M1 & $0.79^{a}$ & $0.79^{a}$ & TLI & & & & & \\
\hline M2 & $0.82^{a}$ & $0.84^{a}$ & RMSEA & & & & & \\
\hline M3 & $0.79^{a}$ & $0.83^{a}$ & SRMR & & & & & \\
\hline $\mathrm{A} 1$ & $0.65^{a}$ & $0.69^{a}$ & 1-factor $\mathrm{m}$ & actor $\mathrm{m}$ & $.93(10)^{a}$ & & & \\
\hline $\mathrm{A} 2$ & $0.50^{\mathrm{a}}$ & $0.65^{a}$ & & & & & & \\
\hline $\mathrm{A} 3$ & $0.52^{\mathrm{a}}$ & $0.64^{a}$ & & & & & & \\
\hline
\end{tabular}

The robust maximum likelihood estimation method was used.

PERMA: Positive emotion, Engagement, Relationships, Meaning, and Accomplishment; P: positive emotion; E: engagement; R: relationships; M: meaning; A: accomplishment; df: degrees of freedom; CFI: comparative fit index; TLI: Tucker-Lewis index; RMSEA: root mean square error of approximation; SRMR: standardized root mean square residual.

${ }^{\mathrm{a} p}<0.05$.

Table 4. Convergent and divergent validity; Pearson's correlations with other scales

\begin{tabular}{|c|c|c|c|c|c|c|c|}
\hline Scale/factors or constructs & Mean & $P$ & $E$ & $\mathrm{R}$ & $M$ & A & Overall \\
\hline \multicolumn{8}{|l|}{ Korean Workplace PERMA-Profiler } \\
\hline Positive emotion & $5.59(1.87)$ & 1.00 & & & & & \\
\hline Engagement & 6.09 (1.67) & $0.80^{\mathrm{a}}$ & 1.00 & & & & \\
\hline Relationship & $6.10(1.60)$ & $0.74^{\mathrm{a}}$ & $0.68^{\mathrm{a}}$ & 1.00 & & & \\
\hline Meaning & $6.30(1.69)$ & $0.78^{a}$ & $0.82^{\mathrm{a}}$ & $0.74^{\mathrm{a}}$ & 1.00 & & \\
\hline Accomplishment & $6.55(1.29)$ & $0.59^{a}$ & $0.68^{\mathrm{a}}$ & $0.56^{\mathrm{a}}$ & $0.69^{\mathrm{a}}$ & 1.00 & \\
\hline Overall well-being & $6.12(1.44)$ & $0.91^{\mathrm{a}}$ & $0.91^{\mathrm{a}}$ & $0.85^{a}$ & $0.92^{\mathrm{a}}$ & $0.78^{\mathrm{a}}$ & 1.00 \\
\hline Negative emotion & $4.68(1.80)$ & $-0.34^{a}$ & -0.09 & $-0.19^{a}$ & $-0.16^{\mathrm{a}}$ & -0.06 & $-0.21^{\mathrm{a}}$ \\
\hline Physical health & $5.32(1.88)$ & $0.55^{\mathrm{a}}$ & $0.45^{\mathrm{a}}$ & $0.53^{\mathrm{a}}$ & $0.53^{\mathrm{a}}$ & $0.40^{\mathrm{a}}$ & $0.57^{a}$ \\
\hline Loneliness & $4.51(2.52)$ & -0.16 & -0.01 & -0.16 & 0.00 & -0.02 & -0.09 \\
\hline MHC-SF & $2.02(0.85)$ & $0.65^{a}$ & $0.57^{a}$ & $0.58^{a}$ & $0.60^{a}$ & $0.48^{\mathrm{a}}$ & $0.67^{a}$ \\
\hline Emotional well-being & $2.23(1.04)$ & $0.58^{\mathrm{a}}$ & $0.50^{\mathrm{a}}$ & $0.46^{\mathrm{a}}$ & $0.46^{\mathrm{a}}$ & $0.39^{a}$ & $0.56^{\mathrm{a}}$ \\
\hline Psychological well-being & $2.12(0.92)$ & $0.60^{a}$ & $0.53^{a}$ & $0.54^{\mathrm{a}}$ & $0.58^{\mathrm{a}}$ & $0.47^{\mathrm{a}}$ & $0.63^{a}$ \\
\hline Social well-being & $1.79(0.92)$ & $0.58^{\mathrm{a}}$ & $0.51^{\mathrm{a}}$ & $0.54^{\mathrm{a}}$ & $0.54^{\mathrm{a}}$ & $0.42^{\mathrm{a}}$ & $0.60^{\mathrm{a}}$ \\
\hline UWES & $3.01(1.19)$ & $0.75^{\mathrm{a}}$ & $0.78^{a}$ & $0.63^{\mathrm{a}}$ & $0.75^{\mathrm{a}}$ & $0.60^{\mathrm{a}}$ & $0.81^{a}$ \\
\hline Vigor & $2.79(1.30)$ & $0.75^{\mathrm{a}}$ & $0.72^{\mathrm{a}}$ & $0.61^{\mathrm{a}}$ & $0.69^{a}$ & $0.52^{\mathrm{a}}$ & $0.77^{a}$ \\
\hline Dedication & $3.10(1.25)$ & $0.70^{\mathrm{a}}$ & $0.74^{\mathrm{a}}$ & $0.59^{a}$ & $0.74^{\mathrm{a}}$ & $0.58^{\mathrm{a}}$ & $0.77^{a}$ \\
\hline Absorption & $3.16(1.27)$ & $0.66^{\mathrm{a}}$ & $0.73^{\mathrm{a}}$ & $0.58^{\mathrm{a}}$ & $0.69^{a}$ & $0.59^{\mathrm{a}}$ & $0.74^{\mathrm{a}}$ \\
\hline KOSS-SF & $2.47(0.34)$ & $-0.59^{a}$ & $-0.37^{a}$ & $-0.47^{a}$ & $-0.42^{\mathrm{a}}$ & $-0.30^{\mathrm{a}}$ & $-0.50^{\mathrm{a}}$ \\
\hline Job demand & $2.55(0.58)$ & $-0.19^{a}$ & 0.03 & -0.10 & -0.01 & 0.01 & -0.07 \\
\hline Insufficient job control & $2.42(0.51)$ & $-0.38^{a}$ & $-0.39^{a}$ & $-0.38^{a}$ & $-0.44^{\mathrm{a}}$ & $-0.43^{a}$ & $-0.45^{a}$ \\
\hline Interpersonal conflict & $2.33(0.53)$ & $-0.46^{a}$ & $-0.33^{a}$ & $-0.48^{a}$ & $-0.36^{a}$ & $-0.21^{\mathrm{a}}$ & $-0.43^{a}$ \\
\hline Job insecurity & $2.41(0.77)$ & $-0.34^{a}$ & $-0.19^{a}$ & $-0.14^{\mathrm{a}}$ & $-0.19^{a}$ & -0.11 & $-0.23^{a}$ \\
\hline Lack of reward & $2.69(0.59)$ & $-0.44^{a}$ & $-0.28^{a}$ & $-0.36^{a}$ & $-0.32^{\mathrm{a}}$ & $-0.16^{a}$ & $-0.37^{a}$ \\
\hline \multicolumn{8}{|l|}{ MBI-GS } \\
\hline Exhaustion & $3.25(1.28)$ & $-0.50^{\mathrm{a}}$ & $-0.28^{a}$ & $-0.26^{a}$ & $-0.29^{a}$ & $-0.19^{a}$ & $-0.37^{a}$ \\
\hline Cynicism & $2.61(1.25)$ & $-0.51^{\mathrm{a}}$ & $-0.47^{a}$ & $-0.37^{a}$ & $-0.48^{a}$ & $-0.38^{a}$ & $-0.51^{a}$ \\
\hline Professional efficacy & $3.85(0.92)$ & $0.47^{a}$ & $0.53^{a}$ & $0.50^{\mathrm{a}}$ & $0.60^{a}$ & $0.64^{\mathrm{a}}$ & $0.61^{a}$ \\
\hline PWI-SF & $23.91(8.45)$ & $-0.62^{a}$ & $-0.44^{a}$ & $-0.45^{a}$ & $-0.47^{a}$ & $-0.30^{a}$ & $-0.50^{a}$ \\
\hline Low social performance and self-confidence & $11.59(3.92)$ & $-0.56^{a}$ & $-0.43^{a}$ & $-0.44^{\mathrm{a}}$ & $-0.47^{\mathrm{a}}$ & $-0.43^{\mathrm{a}}$ & $-0.54^{\mathrm{a}}$ \\
\hline Depression & $2.58(1.93)$ & $-0.47^{a}$ & $-0.31^{\mathrm{a}}$ & $-0.36^{a}$ & $-0.38^{\mathrm{a}}$ & $-0.30^{\mathrm{a}}$ & $-0.43^{\mathrm{a}}$ \\
\hline Sleep disturbance and anxiety & $1.82(1.43)$ & $-0.40^{a}$ & $-0.21^{\mathrm{a}}$ & $-0.25^{\mathrm{a}}$ & $-0.26^{a}$ & $-0.26^{\mathrm{a}}$ & $-0.32^{\mathrm{a}}$ \\
\hline Low general well-being and vitality & $7.91(2.70)$ & $-0.59^{a}$ & $-0.41^{\mathrm{a}}$ & $-0.38^{a}$ & $-0.39^{\mathrm{a}}$ & $-0.31^{\mathrm{a}}$ & $-0.49^{a}$ \\
\hline
\end{tabular}

PERMA: Positive emotion, Engagement, Relationships, Meaning, and Accomplishment; P: positive emotion; E: engagement; R: relationships; M: meaning; A: accomplishment; MHC-SF: Mental Health Continuum-Short Form; UWES: Utrecht Work Engagement Scale; KOSS-SF: Korean Occupational Stress Scale-Short Form; MBI-GS: Maslach Burnout Inventory-General Survey; PWI-SF: Psychosocial Well-being Index-Short Form.

${ }^{\mathrm{a}} \mathrm{p}<0.01$ by Pearson's correlation. 


\section{DISCUSSION}

We translated the Workplace PERMA-Profiler into Korean and conducted a survey of Korean workers. In this study, the Korean version of the Workplace PERMA-Profiler demonstrated good reliability and convergent, divergent, and structural validity. Therefore, it can be used to assess multidimensional well-being in the workplace among Korean workers.

The measure showed strong internal consistency. Cronbach's alpha values for the internal consistency (reliability) of the factors ranged from 0.70 to 0.95 , similar to those for the original PERMA-Profiler (0.69-0.95) [10]. The accomplishment (A) dimension had the lowest internal consistency. Among questions, the mean values of A1 and A3 responses differed the most. Korean workers are probably good at handling (A3) and achieving (A2) work-related matters, but might be less likely to feel that they are making progress towards accomplishing their work-related goals (A1).

The CFA indicated that the 5-factor PERMA model had a marginally acceptable fit $\left[\chi^{2}(80)=\right.$ 383.04, CFI $=0.909, \mathrm{TLI}=0.881, \mathrm{RMSEA}=0.110, \mathrm{SRMR}=0.054 \mathrm{]}$, rather than completely supporting the 5 -factor structure. However, the original PERMA-Profiler (CFI $=0.894$, TLI $=0.864$, RMSEA $=0.107)$ and Japanese Workplace PERMA-Profiler $(\mathrm{CFI}=0.892, \mathrm{TLI}=0.858$, RMSEA $=0.105)$ had similar values $[10,27]$. This marginally acceptable fit suggests that the 5-factor PERMA model might not be the most appropriate model measuring workplace well-being or the items might not adequately separate the 5 factors in the Korean workplace context. For example, Korean workers might consider item E2 ("To what extent do you feel excited and interested in your work?") closer to positive emotion than to engagement. Korean workers may also meet difficulties distinguishing between the concepts of meaning and accomplishment. Further research is needed to investigate how Korean workers understand each scale item using focus group interviews or other applicable methods.

Convergent validity was well supported. Work engagement showed the strongest positive correlations with this measure, especially with the PERMA-E dimension. In addition, the 3 dimensions of mental well-being in life had the strongest positive correlations with the PERMA-P dimension. These results support the postulate that mental well-being in life, work engagement, and occupational well-being are strongly correlated [28]. As engagement has been defined as the opposite experience of burnout, the burnout (exhaustion and cynicism) and engagement (vigor and dedication) scales should be negatively related [29,30]. As expected, our results showed that the core dimensions of burnout (exhaustion and cynicism) were correlated negatively with the PERMA-E dimension. In comparison, professional efficacy showed a moderate positive correlation with the PERMA-E dimension. The low degree of correlation $(r=-0.19)$ between the PERMA-A dimension and exhaustion suggests that these 2 domains are not completely separated because workers might experience exhaustion in the process of work accomplishment.

The work-related psychosocial factors (insufficient job control, interpersonal conflict, and lack of reward) showed moderate negative correlations with the PERMA-P, R, and M dimensions. However, the relationships to job demands were weak. According to the job-demands resources model, well-being at work is not correlated strongly with job demands [31]. Stress responses (low social performance, depression, sleep disturbance, and low general well-being) also had moderate negative correlations with PERMA factors, except A. The PWI-SF is generally used to evaluate psychological well-being by measuring 
psychological distress [24], but it could also be partially applicable to occupational wellbeing, based on our findings.

This study has some limitations. First, the research sample came from a pooled online panel, and selection bias might exist. Second, social desirability bias, which is the tendency of respondents to answer questions to avoid embarrassment and project a favorable image to others, could also exist. Third, the Workplace PERMA-Profiler may not measure all aspects of occupational well-being in the Korean workplace. Since the PERMA theory has been developed and validated in other countries, it may not fully reflect the Korean workplace culture differences. Despite of these limitations, there is no doubt that the Korean Workplace PERMA-Profiler is highly reliable in measuring well-being in workplace. This is the first reported set of norms for the workplace PERMA-Profiler in Korea. Since there is heterogeneity in how well-being can be defined and evaluated, well-being needs to be understood as a multidimensional construct and very different context. The Workplace PERMA-Profiler was developed in the context of occupational setting with 5 domains those help evaluate different aspects of well-being. Given the importance of occupational well-being to healthy living, we propose practical application of the Workplace PERMA-Profiler in evaluating the occupational well-being and a series of changes after psychological interventions.

\section{CONCLUSIONS}

The Korean version of the Workplace PERMA-Profiler showed good reliability and validity. It might be used as a tool to evaluate well-being in the workplace or as an indicator for positive mental health interventions at work.

\section{ACKNOWLEDGEMENTS}

We would like to thank Peggy Kern for reviewing the back-translated script and giving thoughtful opinion and Min Seok Oh, the Korean linguist for advice on Korean grammar and nuance differences after reviewing Korean Profile. Also, we sincerely thank 34 participants in cognitive debriefing session for their opinion.

\section{REFERENCES}

1. Maggino F. Assessing the subjective wellbeing of nations. In: Glatzer W, Camfield L, Møller V, Rojas M, editors. Global handbook of quality of life. New York: Springer; 2015. p.803-22.

2. Diener E, Chan MY. Happy people live longer: subjective well-being contributes to health and longevity. Appl Psychol Health Well Being 2011;3(1):1-43. https://www.ncbi.nlm.nih.gov/entrez/query. fcgi?cmd=Retrieve\&db=PubMed\&list_uids=26286968\&dopt=Abstract PUBMED | CROSSREF

3. Hassan E, Austin C, Celia C, Disley E, Hunt P, Marjanovic S, Shehabi A, van Dijk LV, van Stolk C. Health and wellbeing at work in the United Kingdom. Santa Monica: RAND Corporation; 2009.

4. Kuoppala J, Lamminpää A, Husman P. Work health promotion, job well-being, and sickness absences--a systematic review and meta-analysis. J Occup Environ Med 2008;50(11):1216-27. PUBMED | CROSSREF

5. Schulte P, Vainio H. Well-being at work--overview and perspective. Scand J Work Environ Health 2010;36(5):422-9.

PUBMED | CROSSREF 
6. Tompa E. The impact of health on productivity: empirical evidence and policy implications. In: Banting K, Sharpe A, St-Hilaire F, editors. The review of economic performance and social progress, 2002: towards a social understanding of productivity. Montreal: McGill-Queen's University Press; 2002. p.181-202.

7. Amick BC III, Gimeno D. Measuring work outcomes with a focus on health-related work productivity loss. In: Wittink H, Carr D, editors. Pain management: evidence, outcomes and quality of life: a sourcebook. Amsterdam: Elsevier; 2007. p.329-43.

8. Linton MJ, Dieppe P, Medina-Lara A. Review of 99 self-report measures for assessing well-being in adults: exploring dimensions of well-being and developments over time. BMJ Open 2016;6(7):e010641. PUBMED | CROSSREF

9. Kern ML, Waters LE, Adler A, White MA. A multidimensional approach to measuring well-being in students: application of the PERMA framework. J Posit Psychol 2015;10(3):262-71. PUBMED | CROSSREF

10. Butler J, Kern ML. The PERMA-Profiler: a brief multidimensional measure of flourishing. Int J Wellbeing 2016;6(3):1-48. CROSSREF

11. Lee JY, Kim HY. The effects of emotional labor on burnout: the moderating and mediating effects of flourishing in child care teachers. Korean J Child Stud 2016;37(4):169-79. CROSSREF

12. Kim HM. The relation between signature strengths and well-being and the effect of signature strengths use based intervention on well-being [master's thesis]. Seoul: Ewha Womans University; 2016.

13. Wild D, Grove A, Martin M, Eremenco S, McElroy S, Verjee-Lorenz A, et al. Principles of good practice for the translation and cultural adaptation process for patient-reported outcomes (PRO) measures: report of the ISPOR Task Force for Translation and Cultural Adaptation. Value Health 2005;8(2):94-104. PUBMED | CROSSREF

14. Sousa VD, Rojjanasrirat W. Translation, adaptation and validation of instruments or scales for use in cross-cultural health care research: a clear and user-friendly guideline. J Eval Clin Pract 2011;17(2):268-74. PUBMED | CROSSREF

15. Anthoine E, Moret L, Regnault A, Sébille V, Hardouin JB. Sample size used to validate a scale: a review of publications on newly-developed patient reported outcomes measures. Health Qual Life Outcomes 2014;12:176. PUBMED | CROSSREF

16. Yurdugül H. Minimum sample size for Cronbach's coefficient alpha: a Monte-Carlo study. Hacet U Egitim Fak 2008;35:397-405.

17. Kern ML. The Workplace PERMA Profiler. Pennsylvania: University of Pennsylvania; 2014. http://www. peggykern.org/uploads/5/6/6/7/56678211/workplace_perma_profiler_102014.pdf. Accessed 8 Aug 2019.

18. Lim YJ, Ko YG, Shin HC, Jo YR. Psychometric evaluation of the Mental Health Continuum-Short Form (MHC-SF) in South Koreans. Korean J Psychol Gen 2012;31(2):369-86.

19. Nerstad CG, Richardsen AM, Martinussen M. Factorial validity of the Utrecht Work Engagement Scale (UWES) across occupational groups in Norway. Scand J Psychol 2010;51(4):326-33. PUBMED

20. Kim WH, Park JG, Kwon B. Work engagement in South Korea: validation of the Korean Version 9-Item Utrecht Work Engagement Scale. Psychol Rep 2017;120(3):561-78. PUBMED | CROSSREF

21. Chang SJ, Koh SB, Kang D, Kim SA, Kang MG, Lee CG, et al. Developing an occupational stress scale for Korean employees. Korean J Occup Environ Med 2005;17(4):297-317. CROSSREF

22. Schutte N, Toppinen S, Kalimo R, Schaufeli W. The factorial validity of the Maslach Burnout InventoryGeneral Survey (MBI-GS) across occupational groups and nations. J Occup Organ Psychol 2000;73(1):53-66. CROSSREF

23. Sin KH. The Maslach Bunout Inventory-General Survey (MBI-GS): an application in South Korea. Korean J Ind Organ Psychol 2003;16(3):1-17.

24. Lee CY, Lee JY. Reliability and validity of PWI (Psychosocial Wellbeing Index). Korean J Prev Med 1996;29(2):255-64.

25. Chang SJ, Koh SB, Kang MG, Cha BS, Park JK, Hyun SJ, et al. Epidemiology of psychosocial distress in Korean employees. J Prev Med Public Health 2005;38(1):25-37. PUBMED

26. Cheung GW, Rensvold RB. Evaluating goodness-of-fit indexes for testing measurement invariance. Struct Equ Modeling 2002;9(2):233-55. CROSSREF 
27. Watanabe K, Kawakami N, Shiotani T, Adachi H, Matsumoto K, Imamura K, et al. The Japanese Workplace PERMA-Profiler: a validation study among Japanese workers. J Occup Health 2018;60(5):383-93. PUBMED | CROSSREF

28. Robertson IT, Cooper CL. Full engagement: the integration of employee engagement and psychological well-being. Leadersh Organ Dev J 2010;31(4):324-36. CROSSREF

29. González-Romá V, Schaufeli WB, Bakker AB, Lloret S. Burnout and work engagement: Independent factors or opposite poles? J Vocat Behav 2006;68(1):165-74. CROSSREF

30. Schaufeli WB, Salanova M, González-Romá V, Bakker AB. The measurement of engagement and burnout: a two sample confirmatory factor analytic approach. J Happiness Stud 2002;3(1):71-92. CROSSREF

31. Hakanen JJ, Schaufeli WB, Ahola K. The Job Demands-Resources model: a three-year cross-lagged study of burnout, depression, commitment, and work engagement. Work Stress 2008;22(3):224-41. CROSSREF 
Appendix 1. The Korean Workplace PERMA-Profiler: presented one question per one screen or a full measure as part of a paper questionnaire

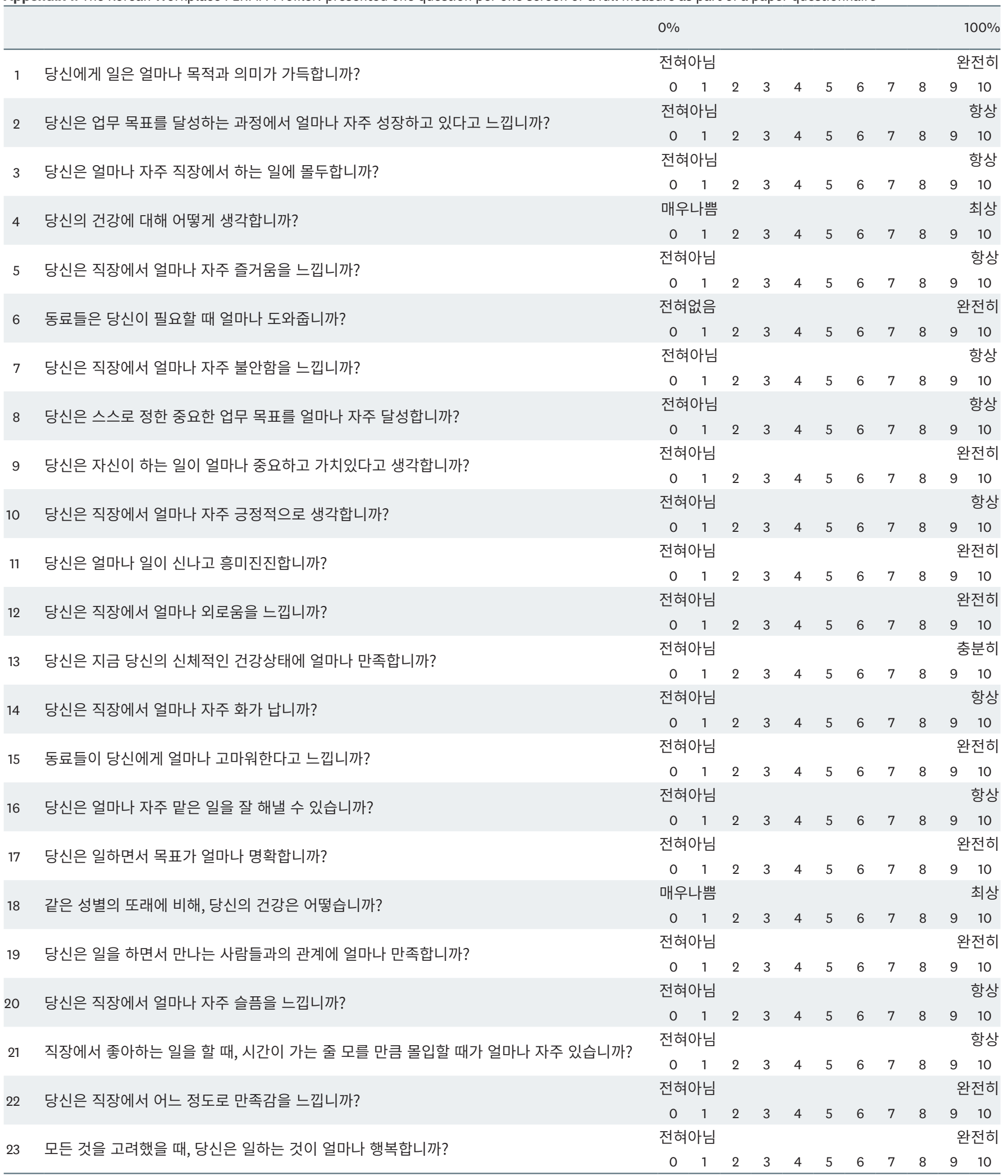


Appendix 2. The Korean Workplace PERMA-Profiler, grouped version: presented each group per a single page Mobile/Web Page 1

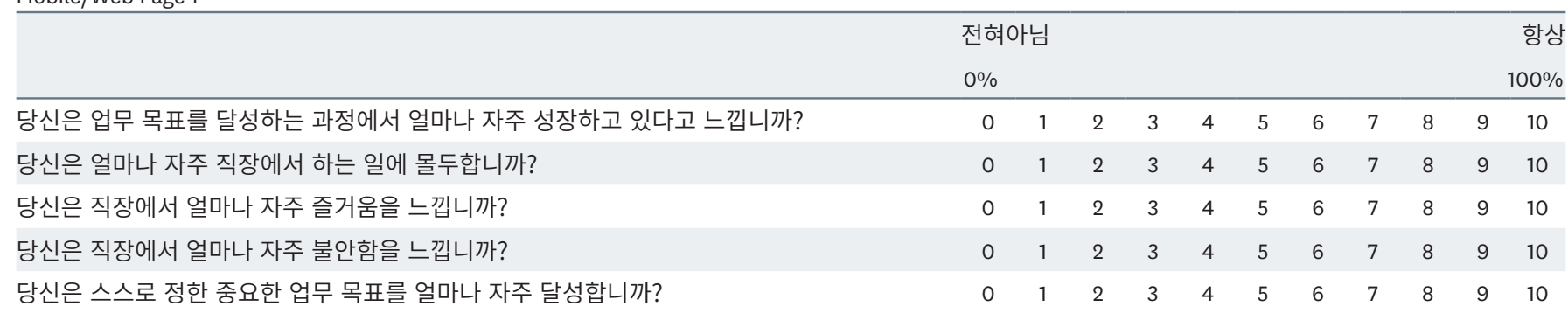

Mobile/Web Page 2

\begin{tabular}{|c|c|c|c|c|c|c|c|c|c|c|c|}
\hline \multirow[b]{2}{*}{ 당신의 건강에 대해 어떻게 생각합니까? } & \multicolumn{9}{|c|}{ 매우나쁨 } & \multicolumn{2}{|c|}{ 매우좋음 } \\
\hline & 0 & 1 & 2 & 3 & 4 & 5 & 6 & 7 & 8 & 9 & 10 \\
\hline
\end{tabular}

Mobile/Web Page 3

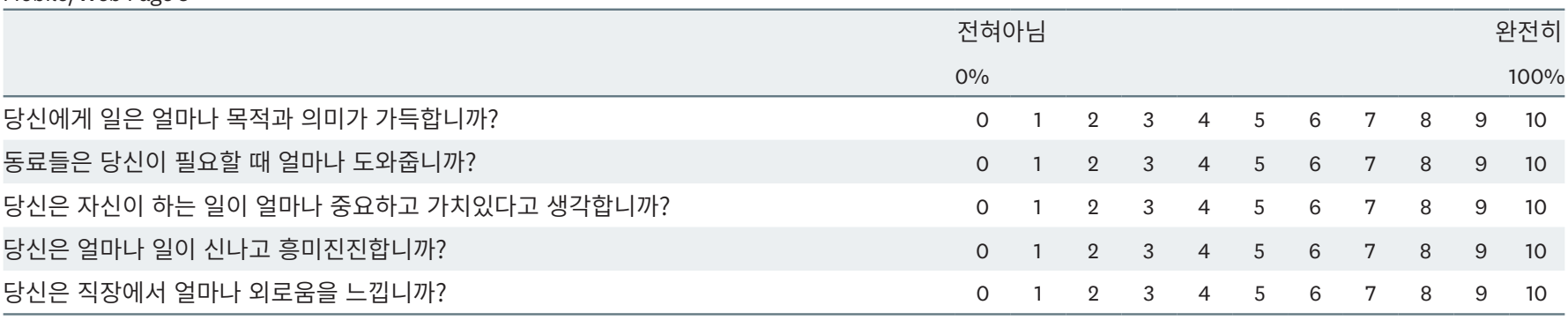

Mobile/Web Page 4

당신은 지금 당신의 신체적인 건강상태에 얼마나 만족합니까?

전혀아님 매우만족

$\begin{array}{lllllllllll}0 & 1 & 2 & 3 & 4 & 5 & 6 & 7 & 8 & 9 & 10\end{array}$

Mobile/Web Page 5

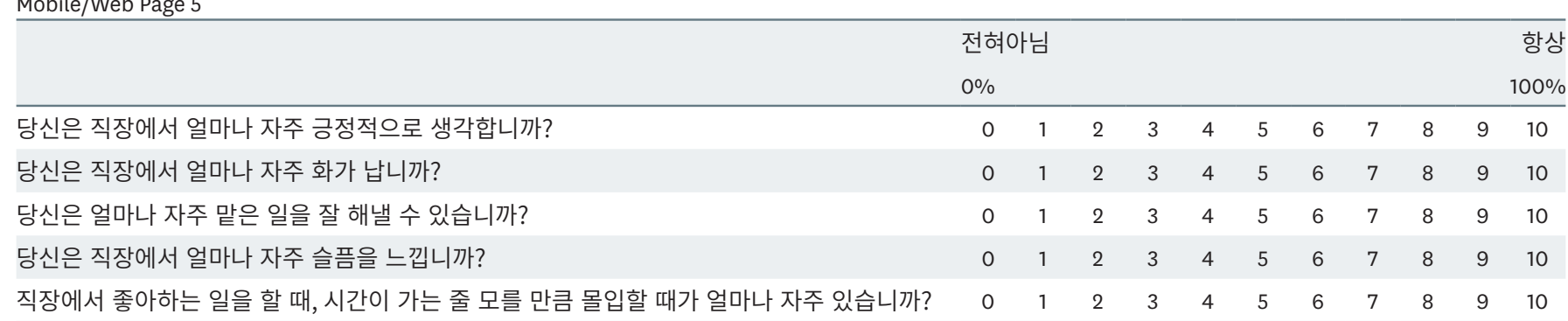

Mobile/Web Page 6

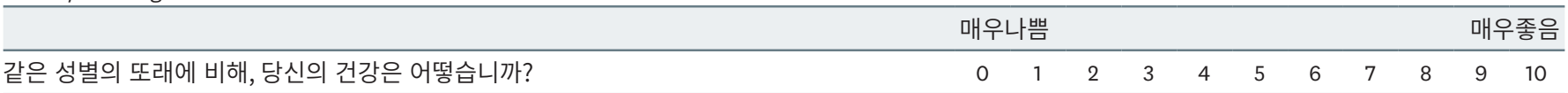

